\title{
Aging skin and non-surgical procedures: a basic science overview
}

\author{
Amy R. Vandiver ${ }^{1}$, Sara R. Hogan ${ }^{1,2}$ \\ 'Division of Dermatology, University of California Los Angeles, Los Angeles, CA 90095, USA. \\ ${ }^{2}$ David Geffen School of Medicine, University of California, Los Angeles, CA 90095, USA.
}

Correspondence to: Dr. Amy R. Vandiver, Division of Dermatology, University of California Los Angeles, 200 Medical Plaza Suite 450, Los Angeles, CA 90095, USA. E-mail: avandiver@mednet.ucla.edu

How to cite this article: Vandiver AR, Hogan SR. Aging skin and non-surgical procedures: a basic science overview. Plast Aesthet Res 2020;7:63. http://dx.doi.org/10.20517/2347-9264.2020.159

Received: 1 Aug 2020 First Decision: 7 Aug 2020 Revised: 10 Sep 2020 Accepted: 12 Oct 2020 Published: 6 Nov 2020

Academic Editor: James E. Zins Copy Editor: Cai-Hong Wang Production Editor: Jing Yu

\begin{abstract}
Skin aging is a major cosmetic concern and associated with extensive changes in skin function and structure. The understanding of the basic science underlying skin aging is rapidly progressing, anchored around nine fundamental hallmarks of aging defined in 2013. Here we present the evidence for the relevance of each hallmark of aging to skin aging, emphasizing the uniquely prominent roles of oxidative damage and the extracellular matrix in photoaging. We review the existing evidence for how established treatments of skin aging target each fundamental hallmark and discuss targets for potential future treatments.
\end{abstract}

Keywords: Aging, photoaging, intrinsic aging, antiaging, rejuvenation

\section{INTRODUCTION}

Skin aging is associated with extensive changes in the structure and function of all aspects of the skin and serves as a major risk factor for multiple pathologies including atopy, impaired wound healing, infection and malignancy ${ }^{[1-5]}$. In addition to functional concerns, the aging of sun-exposed skin, with the face in particular, is a major cosmetic concern prompting patients to seek cosmetic procedures. While therapies to reduce or prevent aging of sun-exposed skin have been present for decades, our understanding of the basic science underlying aging is rapidly evolving, shedding light on the mechanisms of established treatments and identifying new treatment targets and methods. In this article, we will discuss the current

\footnotetext{
(@) $(0$

(C) The Author(s) 2020. Open Access This article is licensed under a Creative Commons Attribution 4.0 International License (https://creativecommons.org/licenses/by/4.0/), which permits unrestricted use, sharing, adaptation, distribution and reproduction in any medium or format, for any purpose, even commercially, as long as you give appropriate credit to the original author(s) and the source, provide a link to the Creative Commons license, and indicate if changes were made.
}

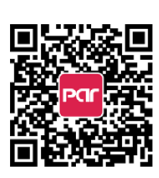


understanding of the hallmarks of aging as applied to skin aging, review how current treatments target this underlying biology and discuss future treatments identified by this emerging knowledge.

\section{SKIN AGING}

The skin consists of two layers with distinct cell populations and underlying biology. The outermost layer, the epidermis, is a stratified epithelium consisting primarily of keratinocytes. The inner most layer of the epidermis consists of proliferating basal keratinocytes, above which are three differentiated layers: the stratum spinosum, stratum granulosum and stratum corneum. The outermost layer, the stratum corneum consists of anucleate corneocytes in a lipid-rich matrix. The epidermis is regenerated by epidermal stem cells, distinct populations of which are found throughout the basal layer of the epidermis and in the hair follicle $e^{[6,7]}$. Below the basal layer of the epidermis lies the dermis which consists of a collagen-rich extracellular matrix (ECM) supporting vasculature and adnexal structures. This matrix is generated by dermal fibroblasts, terminally differentiated cells of mesenchymal origin.

Aging of sun-exposed skin (photoaging) and sun-protected skin (intrinsic or chronological aging) are distinct processes with both common and unique manifestations and molecular mechanisms. Intrinsic aging is commonly associated with increased xerosis (dry skin), fine rhytids and laxity. Photoaging shares these features but also exhibits uneven pigmentation, deeper rhytids, telangiectasias and increased growth rate of malignant neoplasms. Histologically, photoaging demonstrates uneven thinning of the epidermal layer with thickening of the granular layer and more compact corneal layer, dermal ECM loss of collagen and elastin, as well as increased dermal inflammation ${ }^{[8-11]}$. Such histologic findings correlate with increased gene expression of matrix metalloproteinases and decreased gene expression of ECM components, particularly collagen and elastin. These changes are seen in multiple models of photoaging, and as such have been used as markers in many mechanistic and therapeutic studies ${ }^{[12-15]}$.

Investigation into the basic biology of aging has steadily grown since the 1980s. Original studies focused on identifying a single driving mechanism. However, in 2013, López-Otín et al ${ }^{[16]}$ proposed a distinct framework for studying aging biology focused on nine hallmarks of aging, which together contribute to age-related functional change. This marked a shift towards understanding aging not as a single process, but instead as a combination of biological changes. These hallmarks are broken into three categories: primary, antagonistic and integrative [Table 1]. The primary hallmarks of genomic instability, epigenetic change, loss of proteostasis and telomere attrition, are the foundational changes that initiate aging phenotypes. Antagonistic hallmarks occur in response to these alterations and include de-regulation of nutrient sensing, mitochondrial dysfunction and cellular senescence. Together, these all contribute to the integrative hallmarks - impaired intracellular communication and stem cell exhaustion - which most directly contribute to tissue aging phenotypes.

Since publication, López-Otín et al. ${ }^{[16]}$ s hallmarks of aging have been widely accepted and used extensively as a framework for aging research. It is increasingly recognized, however, that each tissue and cell population ages in a distinct manner, with differing hallmarks playing a more prominent role for each ${ }^{[17]}$. While photoaging shares the majority of the hallmarks of aging seen across cell types, we will discuss evidence that the central role of ultraviolet (UV) exposure and prominence of the ECM in aging biology make the damage and signaling associated hallmarks particularly relevant. Below, we will review each of the hallmarks of aging as applied to skin aging and discuss treatment modalities targeting each set of changes.

\section{Primary hallmarks of skin aging}

\section{Genomic instability}

In photoaging, UV radiation plays a prominent role in inducing the primary hallmarks of aging, particularly genomic instability. UV radiation is linked to DNA damage in vivo and in cell culture. UVB 
Table 1. Hallmarks of aging

\begin{tabular}{|c|c|c|c|}
\hline & Molecular target & Treatment & Level of evidence \\
\hline \multirow[t]{7}{*}{ Primary hallmarks } & DNA damage & Antioxidant supplementation & III \\
\hline & & Photodynamic therapy & I \\
\hline & Epigenetic change & Antioxidant supplementation & Not examined \\
\hline & Loss of protein homeostasis & Antioxidant supplementation & Not examined \\
\hline & & Laser resurfacing & $\mathrm{V}$ \\
\hline & & $\begin{array}{l}\text { Fractional radiofrequency } \\
\text { microneedling }\end{array}$ & IV \\
\hline & Telomere shortening & None & None \\
\hline \multirow[t]{9}{*}{ Antagonistic hallmarks } & Mitochondrial dysfunction & Coenzyme Q10 supplementation & III \\
\hline & & Nicotinamide supplementation & III \\
\hline & & Low level light treatment & III \\
\hline & Impaired nutrient sensing & & \\
\hline & Increased mTOR & Rapamycin & VI \\
\hline & Decreased AMPK & Metformin & None \\
\hline & & Resveratrol & $\mathrm{V}$ \\
\hline & Decreased sirtuins & Resveratrol & $\mathrm{V}$ \\
\hline & Senescent cells & Senolytics in development & None \\
\hline \multirow[t]{11}{*}{ Integrative hallmarks } & Altered intracellular signaling & & \\
\hline & Altered growth factors & Topical growth factors & $\mathrm{V}$ \\
\hline & & Platelet-rich plasma & $\mathrm{V}$ \\
\hline & Altered inflammatory signaling & Laser resurfacing & II \\
\hline & & Chemical peels & III \\
\hline & & Microdermabrasion & III \\
\hline & & $\begin{array}{l}\text { Fractional radiofrequency } \\
\text { microneedling }\end{array}$ & IV \\
\hline & Altered ECM signaling & Topical retinoids & I \\
\hline & & Exogenous filler & III \\
\hline & & PDO and PLA threads & VI \\
\hline & Stem cell exhaustion & $\begin{array}{l}\text { Mesenchymal stem cell } \\
\text { transplantation }\end{array}$ & $\mathrm{V}$ \\
\hline
\end{tabular}

PDO: Polydioxanone; PLA: poly-lactic acid; ECM: extracellular matrix

exposure leads to the formation of cyclobutane dimers in the nuclear genome ${ }^{[18]}$. UVA exposure causes the generation of reactive oxidative species (ROS) and oxidative guanine damage ${ }^{[19]}$. Upon nucleic acid repair, both of these changes induce cytosine to thymidine nucleic acid sequence alterations, which, depending on location, leads to gene dysregulation. These UV-induced mutations in specific genes are linked to skin cancer and loss-of-cell function ${ }^{[20-23]}$. UVA exposure also leads to large modifications in the circular mitochondrial genome, which lacks many of the repair mechanisms that maintain the nuclear genome: photoaged skin is repeatedly observed to contain large deletions in the mitochondrial genome in vivo, and UVA directly induces these changes in cell culture ${ }^{[24-27]}$. Similar mutations are linked to mitochondrial dysfunction in other organ systems ${ }^{[28]}$.

\section{Epigenetic alterations}

In addition to the sequence itself, expression of the nuclear genome is very closely regulated by the epigenome through modifications of the nucleotides and proteins involved in DNA packaging ${ }^{[29]}$. With both intrinsic aging and photoaging, epidermal tissue shows loss of methylation of cytosine bases, with a larger degree of loss in photoaged tissue $e^{[30,31]}$. Compared to sun-protected skin, sun-exposed skin also demonstrates changes in histone modifications, specifically increases in open areas of chromatin that are permissive to gene expression ${ }^{[32]}$. At least some of these changes are directly linked to UV-induced ROS, 
which directly trigger de-methylation in vitro ${ }^{[33]}$. The loss of cytosine methylation and increase in histone acetylation are both linked to increased "transcriptional noise", or low-level transcription of unnecessary genes thought to interfere with cell function in other systems ${ }^{[34,35]}$.

\section{Telomere attrition}

The nuclear genome, mitochondrial genome and epigenome are all clearly demonstrated to change in photoaged skin. It is less clear if changes in the length of telomeric end sequences are prominent in skin aging. Decreases in telomere length occur in dividing cells that lack the enzyme telomerase, and this has been shown to occur more with in association with increased levels of ROS in cultured fibroblasts ${ }^{[36]}$. Such decreases are strongly associated with aging phenotypes in mice ${ }^{[37]}$. However, the relationship between telomere length and human biological age is less direct ${ }^{[38]}$. For skin in particular, the relevance of shortened telomere sequences to epidermal and dermal aging phenotypes remains unclear. While some studies have documented significant decrease in telomere length in skin with age ${ }^{[39-41]}$, there appear to be equivalent levels of change in photoaged and intrinsic aged samples. In addition, studies focused on the epidermis suggest telomerase may be expressed in basal keratinocytes and increase with sun exposure and inflammation ${ }^{[42-44]}$, correlating with a low magnitude of telomere length decrease with age ${ }^{[43]}$.

\section{Loss of proteostasis}

Beyond the genome, aging is associated with notable loss of regulation of protein homeostasis - or "proteostasis". In healthy cells, proteostasis is maintained by the proteasome, an enzyme complex that balances new protein synthesis with damaged protein degradation ${ }^{[45]}$. In photoaging, increased levels of ROS in vivo lead to dermal accumulation of oxidatively modified and damaged proteins and cellular dysfunction ${ }^{[46]}$. In concert, proteasome components decrease in photoaged and intrinsically aged skin ${ }^{[47,48]}$.

\section{Targeting the primary hallmarks of aging}

UV-induced ROS play a clear role in generating many of the primary insults thought to initiate cutaneous aging phenotypes. The endogenous antioxidant system consists of non-enzymatic antioxidants, which acquire electrons to neutralize ROS, and enzymatic antioxidants, which deactivate ROS (A complete discussion of the antioxidant system in skin is available $\left.{ }^{[49]}\right)$. As such, classic antiaging treatments focus on preventing skin damage by decreasing levels of ROS through topical and oral supplementation of components of this system.

A wide range of endogenous non-enzymatic antioxidants are used in topical antiaging formulations. Examples include vitamin C, vitamin E, niacinamide, lycopene, carotenoids and polyphenols ${ }^{[49]}$. Resveratrol, a polyphenol, also increases synthesis of glutathione, an endogenous enzymatic antioxidant ${ }^{[50]}$. In cell culture models, supplementation with vitamin C directly prevents UV-induced DNA damage and increases expression of the proteasome to scavenge damaged proteins and supplementation with niacinamide enhances repair of UV-induced damage ${ }^{[51,52]}$. Clinically, topical application of vitamins $\mathrm{C}$ and E, polyphenols and resveratrol show efficacy in reducing acute UV-induced erythema and DNA damage markers ${ }^{[53-56]}$.

Oral antioxidant formulations are protective against acute UV-induced damage. Oral supplementation with multiple non-enzymatic antioxidants have been demonstrated to decrease UV-induced erythema, inflammatory markers and the incidence of actinic keratoses ${ }^{[57]}$. Systemic reviews, however, suggest that certain oral antioxidant formulations may be associated with increased mortality, likely given the beneficial role of an appropriate level of ROS in many body systems ${ }^{[58]}$.

Still, both topical and oral antioxidant formulations primarily show benefit for preventing - not reversing - photoaging damage. There is evidence that vitamin C supplementation in vitro increases collagen 
synthesis and topical combinations result in modest photoaging benefits, but it is not known whether levels of existing damage are altered ${ }^{[59]}$. Furthermore, while ROS have been directly linked to nuclear and mitochondrial genome impairment, epigenetic change and protein oxidation, no study has demonstrated a reduction of these specific alterations after topical or oral treatment. The exact degree to which these changes are prevented or reversed remains unknown.

Destructive treatments targeting oxidatively damaged cells are shown to have clinical benefit for photoaging. Photodynamic therapy - in which aminolevulinic acid is activated by visible light to destroy rapidly proliferating cells - decreases damaged cells within the epidermis (as noted by p53 expression), promotes collagen synthesis and improves clinical photoaging grade ${ }^{[60]}$. Energy- and laser-based therapies such as radiofrequency microneedling, fractional non-ablative laser and fractional ablative laser, all induce broad destruction of tissue, including the destruction of cells containing oxidatively damaged DNA and proteins. While the level of oxidative damage post-treatment has not been specifically tested, these treatments are shown to induce the expression of specific heat shock proteins known to promote the clearance of damaged proteins ${ }^{[61-63]}$.

\section{Antagonistic hallmarks of aging in photoaging}

\section{Mitochondrial dysfunction}

Mitochondria serve as the primary energy-generating powerhouses of the cell. The number, morphology and activity of mitochondria are closely regulated in numerous biological conditions ${ }^{[64]}$. Possibly related to the accumulation of mitochondrial DNA (mtDNA) alterations as discussed above, there is growing evidence of mitochondrial dysfunction involving altered oxidative phosphorylation in photoaged skin.

In vivo imaging of photoaged epidermis demonstrates a more fragmented mitochondrial network, which may correlate with altered aerobic function ${ }^{[65]}$. Cultured keratinocytes also show decreased electron transport chain (ETC) activity and thus decreased oxidative phosphorylation and a shift to anaerobic metabolism with photoaging ${ }^{[66]}$. A direct relationship between mitochondrial dysfunction and skin aging phenotypes is supported by multiple mouse models: in mouse models in which mitochondrial antioxidants or transcription factors are reduced, keratinocyte differentiation is impaired and increased senescence keratinocytes noted ${ }^{[67,68]}$, and in a model in which mtDNA is progressively decreased, dermal atrophy, increased MMP-1 expression and epidermal hyperplasia are noted ${ }^{[69]}$. In vitro, the restoration of ETC activity is shown to decrease MMP1 expression after UVA radiation, further suggesting a direct link between mitochondrial function and aging phenotypes ${ }^{[66]}$.

\section{Impaired nutrient sensing}

Closely linked to mitochondrial dysfunction and aerobic metabolism alteration, there is significant evidence that nutrient sensing is linked to photoaging. Nutrient sensing is the mechanism by which cells recognize and respond to energy substrates. The concept of impaired nutrient sensing stems from genetic evidence suggesting that those gene variants most linked to lifespan occur within pathways involved in sensing nutrient abundance ${ }^{[70]}$. Models suggest that upregulation of the protein mTOR kinase, which signals nutrient abundance, is associated with aging, and that proteins that signal nutrient scarcity, such as AMPK and sirtuins, are downregulated ${ }^{[71]}$. In mouse models of photoaging, mTOR components are increased and AMPK is decreased ${ }^{[72,73]}$. Similarly, sirtuins are noted to be decreased in fibroblasts isolated from both sunexposed and photoaged individuals ${ }^{[74-76]}$. While these alterations infer that aged skin is signaling a state of nutrient excess, metabolomic profiling of epidermal samples suggests there is downregulation of anabolic biosynthetic pathways and upregulation of catabolic pathways, consistent with an overall impaired function of nutrient sensing ${ }^{[77,78]}$. 


\section{Accumulation of senescent cells}

Senescent cells are those that have permanently exited the replicative cell cycle, and accumulation of these cells has been observed with the aging of many tissues. Despite stopping replication, they are metabolically active and have a distinct secretory profile known as the senescence-associated secretory phenotype (SASP) which can have profound effects on surrounding cells ${ }^{[79,80]}$. The induction of senescence is strongly linked to DNA damage as well as epigenetic changes and loss of proteostasis, so it is not surprising that the presence of senescent cells is significantly increased in photoaged epidermis and dermis ${ }^{[81]}$. In addition, mTOR activity is linked to the induction of senescence in keratinocytes, indicating that the accumulation of senescent cells in photoaged skin is multifactorial ${ }^{[82]}$. The presence of senescent cells in photoaged skin has been linked to photoaging phenotypes in cell culture models: senescent fibroblasts promote ECM degradation through increased MMP-1 secretion and induce a proinflammatory environment, which can promote ECM degradation and keratinocyte tumorigenesis ${ }^{[79,83]}$. Also, the introduction of senescent fibroblasts into organotypic skin models induces thinning of the epidermis and decreased barrier function in the overlying epidermis ${ }^{[84]}$.

\section{Targeting the antagonistic hallmarks of aging}

Given the evidence for mitochondrial dysfunction and impaired nutrient sensing in aging phenotypes, there is a move to target aging treatment and prevention at these deficits, both by improving mitochondrial function and reversing the signals of nutrient abundance. Mitochondrial dysfunction can be mitigated in vivo through supplementation with specific antioxidants. Supplementation with coenzyme Q10, which acts as a diffusible electron transporter in the mitochondrial transport chain, is shown to improve mitochondrial function in multiple oxidative systems in $v i v o^{[85,86]}$ and restore oxidative metabolism in aged keratinocytes in $v^{i t r}{ }^{[66,87]}$. Nicotinamide, which acts as a precursor of the main oxidative substrate NAD+, is also shown to improve mitochondrial quality and promote keratinocyte regenerative capacity in vitro $^{[88,89]}$.

In addition to working as an antioxidant, resveratrol exerts antiaging effects through benefits to mitochondrial function and modifications in nutrient sensing. Resveratrol promotes oxidative metabolism through multiple pathways. In vivo and in vitro, resveratrol activates the nutrient sensor AMPK and thereby activates sirtuin $1^{[90-92]}$ to shift cells to a state of nutrient deficiency ${ }^{[93]}$. Through sirtuin 1, resveratrol directly increases the synthesis of new mitochondria in multiple tissues ${ }^{[94]}$. While this highlights resveratrol as an appealing option for topical therapy, current small trials of topical formulations have unclear evidence of benefit and the bioavailability of these formulations remains questionable ${ }^{[50,95,96]}$.

Low-level light therapy is promoted to treat photoaging through improving mitochondrial function. This treatment involves exposing target tissue to low levels of red or near infrared light and is rising in popularity as many devices can be used for home treatment ${ }^{[97]}$. In vitro studies have shown that specific wavelengths of red and near infrared light are absorbed by cytochrome oxidase c, an enzyme involved in the mitochondrial ETC, and that this absorption increases mitochondrial enzyme activity and energy production ${ }^{[98-100]}$. This increased mitochondrial activity is in turn shown to increase collagen production and growth factor secretion in cultured fibroblasts ${ }^{[101,102]}$, and multiple small trials of low-level light therapy demonstrate modest to moderate benefit for facial rhytids ${ }^{[103,104]}$.

Though not yet available for use on skin, multiple metabolic regulatory molecules studied for systemic antiaging have potential for use as topical therapies. Metformin, developed for use in diabetes mellitus, works as an AMPK activator to alter the cell metabolic profile. In fibroblast culture, metformin stimulates collagen production, and topical formulations promote wound healing and barrier integrity in mouse models ${ }^{[74,105]}$. Recent advances in topical formulations of metformin that permeate human skin suggest this may emerge as an antiaging treatment option ${ }^{[106]}$. Similarly, topical formulations of rapamycin, an mTOR inhibitor, reduce markers of cutaneous aging in human skin in addition to other aging models ${ }^{[107,108]}$. 
Rapamycin was noted, however, to have negative effects on wound healing and thus requires further study before use for antiaging ${ }^{[74]}$.

Another future treatment strategy involves directly targeting senescent cells for removal. Due to their altered signaling profile, senescent cells can theoretically be targeted for destruction via compounds specific to their upregulated components. In transgenic mouse models, the selective apoptosis of cells entering senescence prevents many aging phenotypes but imparts minimal effect on dermal thickness and also delays wound healing ${ }^{[109,110]}$. Multiple compounds that target molecules upregulated in senescent cells, known as senolytics, including dasatinib, quercetin, navitoclax and piperlongumine show efficacy in clearing senescent fibroblasts and other cell populations in culture; however, none have been reported to have efficacy for skin aging phenotypes in vivo at this time ${ }^{[11-114]}$.

\section{Integrative hallmarks of aging}

Altered intracellular signaling

The end points of the primary and antagonistic hallmarks of aging lead to the integrative hallmarks, specifically impaired intracellular communication and stem cell exhaustion.

The most prominent age-related change in intracellular communication is increased inflammation mediated by NF-kappaB (NF- $\kappa \mathrm{B})$, which leads to upregulation of IL-1B, tumor necrosis factor and interferon signaling, and overall decline in adaptive immune function ${ }^{[16]}$. In the epidermis, increased NF- $\mathrm{B}$ signaling is inducible by UV exposure and promotes epidermal stem cell dysfunction ${ }^{[82,115]}$. When NF- $\mathrm{B}$ is inhibited in mouse models, intrinsic aging phenotypes are reversed ${ }^{[16]}$. In addition, photoaged skin also exhibits decreases in other cytokines, such as TGF-B and fibroblast growth factor (FGF), which promote collagen synthesis and epidermal regeneration ${ }^{[17]}$.

In photoaging, the ECM plays a uniquely important role in mediating intracellular signaling. Photoaging is strongly associated with the degradation of collagen in the dermal ECM. This change is initiated by UVinduced increase in MMP secretion by basal keratinocytes and dermal fibroblasts, and is associated with the activation of AP-1 signaling ${ }^{[13]}$. Once degraded, collagen is present within the matrix, and in vitro studies suggest this amplifies intracellular aging. Dermal fibroblasts grown on synthetically-degraded collagen generate increased ROS, increased MMP secretion, and decreased collagen production ${ }^{[13]}$. MMP expression in co-culture fibroblasts also decreases the regenerative capacity and longevity of epidermal stem cells ${ }^{[118]}$.

\section{Stem cell exhaustion}

The final integrative hallmark of aging is stem cell exhaustion, which has a notable role in the epidermal photoaging phenotypes. Two distinct stem cell populations - epidermal and hair follicle stem cells - are thought to maintain the epidermis in different biological settings ${ }^{[6,7]}$. While decreased regeneration and epidermal thinning is noted with both murine and human aging, the specific changes to these stem cell populations is complex and continues to be investigated. In vivo, multiple studies have demonstrated consistent or increased numbers of stem cells in intrinsically aged human and mouse $\operatorname{skin}^{[119-121]}$; however, other studies have demonstrated decreased stem cell functional markers in intrinsically aged and photoaged skin, possibly partially linked to UV-induced basement membrane changes ${ }^{[122-124]}$. In photoaging, this is likely directly linked to many of the previously discussed UV-induced hallmarks, including the DNA-damage response, increased NF-kB signaling, metabolic dysregulation through mTOR upregulation, senescence and ECM degradation, emphasizing the inter-related nature of all aging hallmarks in cutaneous photoaging $[82,114,116,118,121,125]$ 


\section{Targeting altered intracellular signaling and stem cell exhaustion}

As evidence grows of photoaging-induced impairment in signaling molecules, various approaches have been tested to reverse this change. Researchers have attempted to directly supplement certain growth factors that decline with age. Multiple small trials show clinical benefit with topical formulations of growth factors and cytokines, including TGF-beta, platelet-derived growth factor (PDGF), FGF, IL-1 and TNFalpha, in reducing fine lines and wrinkles and increasing dermal collagen ${ }^{[126-128]}$. The true efficacy of these topicals, however, is questionable. Growth factors and cytokines are large, hydrophilic molecules with greater than 15,000 Da molecular weight, and prior studies demonstrate that hydrophilic molecules greater than 500 Da have low penetration past the stratum corneum ${ }^{[129]}$.

Treatments that directly target ECM degradation and associated signaling amplification alteration are more effective. Topical retinoids are well established as clinically effective treatments for photoaging. Retinoids decrease AP-1 and NF-kB signaling and increase TGF-beta signaling to reduce expression of MMPs, and this in turn decreases degraded collagen levels associated with altered cell function ${ }^{[130,131]}$.

In multiple biological systems, dermal fillers that artificially restore the matrix on which fibroblasts live, are demonstrated to increase collagen synthesis. This is likely accomplished by interrupting the defective signaling associated with fragmented collagen. Hyaluronic acid fillers, in human and mouse models, restore the ECM via dermal fibroblast collagen synthesis. In mouse models, hyaluronic acid filler also stimulates collagen and elastin synthesis ${ }^{[132,133]}$. Calcium hydroxylapatite, a semi-permanent biostimulatory filler, is also shown in tissue culture to restore the contractile properties of photoaged dermal fibroblasts ${ }^{[134]}$.

Absorbable sutures are an emerging treatment that may also work through interruption of the altered signaling that is associated with fragmented collagen. Polydioxanone (PDO) and monofilament poly-lactic acid (PLA) absorbable sutures are posited to lift and tighten aging skin. In animal models, PDO and PLA threads on histology induce collagen- 1 and -3 production two weeks after insertion. This benefit, however, sharply declines by 12 weeks post-insertion ${ }^{[135]}$. In another study, PDO sutures induced neocollagenesis, tissue contracture and improved vasculature four weeks after insertion, a change maintained at 48 weeks ${ }^{[136]}$. While molecular analysis has yet to be performed, it is possible that absorbable sutures induce physical contraction of skin and fibrosis to restore the stretch placed on fibroblasts, similar to an intact ECM.

Microdermabrasion, moderate to deep chemical peels, fractional radiofrequency microneedling, and fractional non-ablative and fractional ablative lasers, all demonstrate an induced wound repair response on histology ${ }^{[137-139]}$. Recent molecular analysis suggests that fractionated ablative $\mathrm{CO}_{2}$ laser accomplishes this through alteration of inflammatory signal pathways, with damage-activating innate immune responses that in turn trigger the activation of retinoic acid-dependent pathways ${ }^{[140]}$. Interestingly, this process is mediated by NF-kB expression at significantly higher levels than those observed in chronically aged skin, indicating that the balance of signaling factors is crucial to regenerative responses.

Platelet-rich plasma (PRP) is an autologous blood product of concentrated platelets delivered via injection into target tissue. PRP is thought to contain over 800 bioactive molecules derived from platelet granules, including TGF-beta, epidermal growth factor, PDGF, FGF, IGF and angiogenic growth factors ${ }^{[141,142]}$. While demonstrated to have benefit for wound healing, arthritis, and more recently androgenetic alopecia, its use for photoaging is less well established. A systemic meta-analysis concluded modest clinical benefit of PRP for aging skin, mostly when used as an adjuvant following fractional and fully ablative laser resurfacing ${ }^{[143]}$.

Many of the treatments discussed above target photoaging-related stem cell exhaustion but do not directly restore the stem cell population that is depleted with aging. The direct delivery of stem cells to target tissue has been used in many models of regeneration. Transplanted epidermal stem cells exhibit 


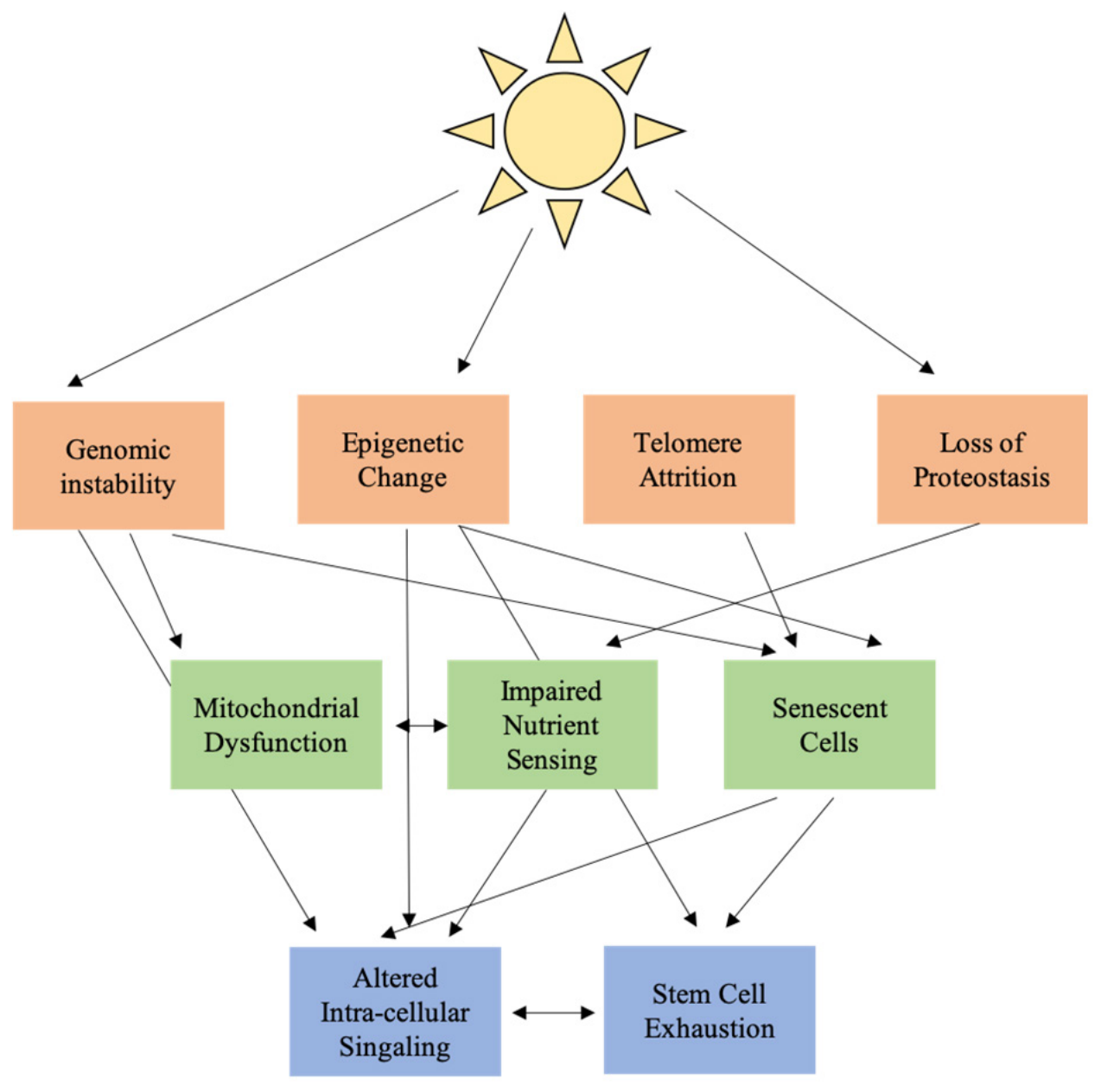

Figure 1. Interconnected hallmarks of aging in cutaneous photoaging

benefit the regeneration of epidermis lost in wound settings but have not been used for regeneration of intact photoaged epidermis ${ }^{[144]}$. Transplantation of an alternate cell population, that of adipose-derived mesenchymal stem cells, has benefit in vivo for both dermal and epidermal aging phenotypes ${ }^{[145]}$. The mechanism of action is unclear, but co-culture experiments demonstrate improved fibroblast synthetic function, suggesting the modification of the signaling milieu rather than direct stem cell regeneration ${ }^{[146]}$.

\section{CONCLUSION}

Skin photoaging is associated with extensive functional and cosmetic changes. The classic hallmarks of systemic aging offer a framework for understanding the process of these changes on a molecular level [Figure 1]. In this framework, UV radiation works through ROS to induce primary changes in the nuclear genome, mitochondrial genome, epigenome and cell protein population. These primary changes lead to antagonistic changes in cell function, impaired mitochondrial function, dysregulated nutrient sensing and cellular senescence. Antagonistic changes result in altered cellular signaling and stem cell exhaustion, particularly increased low level NF-kB inflammatory signaling and decreased growth factor signaling, further amplified by changes in the ECM. Most current effective treatments for photoaging focus on the mitigation of ROSassociated damage through antioxidant supplementation and restoration of the intracellular signaling environment. Open areas for therapy include a focus on mitochondrial function and the process of nutrient sensing and clearance of senescent cells. 


\section{DECLARATIONS}

\section{Authors' contributions}

Made substantial contributions to conception and design of the review and performed data acquisition:

Vandiver AR, Hogan SR

\section{Availability of data and materials}

Not applicable.

\section{Financial support and sponsorship}

None.

\section{Conflicts of interest}

Both authors declared that there are no conflicts of interest.

\section{Ethical approval and consent to participate}

Not applicable.

\section{Consent for publication}

Not applicable.

\section{Copyright}

(C) The Author(s) 2020.

\section{REFERENCES}

1. Yaar M, Eller MS, Gilchrest BA. Fifty years of skin aging. J Investig Dermatol Symp Proc 2002;7:51-8.

2. Ghadially R, Brown BE, Sequeira-Martin SM, Feingold KR, Elias PM. The aged epidermal permeability barrier. Structural, functional, and lipid biochemical abnormalities in humans and a senescent murine model. J Clin Invest 1995;95:2281-90.

3. Rogers HW, Weinstock MA, Feldman SR, Coldiron BM. Incidence estimate of nonmelanomaskin cancer (keratinocyte carcinomas) in the U.S. population, 2012. JAMA Dermatol 2015;151:1081-6.

4. Sauder DN. Effect of age on epidermal immune function. Dermatol Clin 1986;4:447-54.

5. Gould L, Abadir P, Brem H, et al. Chronic wound repair and healing in older adults: current status and future research. J Am Geriatr Soc 2015;63:427-38.

6. Jones PH, Harper S, Watt FM. Stem cell patterning and fate in human epidermis. Cell 1995;80:83-93.

7. Taylor G, Lehrer MS, Jensen PJ, Sun T, Lavker RM. Involvement of follicular stem cells in forming not only the follicle but also the epidermis. Cell 2000;102:451-61.

8. Bhawan J, Andersen W, Lee J, Labadie R, Solares G. Photoaging versus intrinsic aging: a morphologic assessment of facial skin. J Cutan Pathol 1995;22:154-9.

9. Yaar M, Gilchrest BA. Skin aging: postulated mechanisms and consequent changes in structure and function. Clin Geriatr Med 2001; 17:617-30, v.

10. Cinotti E, Bovi C, Tonini G, et al. Structural skin changes in elderly people investigated by reflectance confocal microscopy. $J$ Eur Acad Dermatol Venereol 2020; doi: 10.1111/jdv.16466.

11. Bosset S, Bonnet-Duquennoy M, Barré P, et al. Photoageing shows histological features of chronic skin inflammation without clinical and molecular abnormalities. Br J Dermatol 2003;149:826-35.

12. Khorramizadeh MR, Tredget EE, Telasky C, Shen Q, Ghahary A. Aging differentially modulates the expression of collagen and collagenase in dermal fibroblasts. Mol Cell Biochem 1999;194:99-108.

13. Fisher GJ, Wang ZQ, Datta SC, Varani J, Kang S, Voorhees JJ. Pathophysiology of premature skin aging induced by ultraviolet light. $N$ Engl J Med 1997;337:1419-28.

14. Cho BA, Yoo SK, Seo JS. Signatures of photo-aging and intrinsic aging in skin were revealed by transcriptome network analysis. Aging (Albany NY) 2018;10:1609-26.

15. Lago JC, Puzzi MB. The effect of aging in primary human dermal fibroblasts. PLoS One 2019;14:e219165.

16. López-Otín C, Blasco MA, Partridge L, Serrano M, Kroemer G. The hallmarks of aging. Cell 2013;153:1194-217.

17. Spehar K, Pan A, Beerman I. Restoring aged stem cell functionality: Current progress and future directions. Stem Cells 2020;38:1060-77.

18. Besaratinia A, Synold TW, Chen HH, et al. DNA lesions induced by UV A1 and B radiation in human cells: comparative analyses in the overall genome and in the p53 tumor suppressor gene. Proc Natl Acad Sci U S A 2005;102:10058-63. 
19. Kvam E, Tyrrell RM. Induction of oxidative DNA base damage in human skin cells by UV and near visible radiation. Carcinogenesis 1997;18:2379-84

20. Pickering CR, Zhou JH, Lee JJ, et al. Mutational landscape of aggressive cutaneous squamous cell carcinoma. Clin Cancer Res 2014;20:6582-92.

21. Inman GJ, Wang J, Nagano A, et al. The genomic landscape of cutaneous SCC reveals drivers and a novel azathioprine associated mutational signature. Nat Commun 2018;9:3667.

22. Jayaraman SS, Rayhan DJ, Hazany S, Kolodney MS. Mutational landscape of basal cell carcinomas by whole-exome sequencing. J Invest Dermatol 2014;134:213-20.

23. Bonilla X, Parmentier L, King B, et al. Genomic analysis identifies new drivers and progression pathways in skin basal cell carcinoma. Nat Genet 2016;48:398-406.

24. Yang JH, Lee HC, Wei YH. Photoageing-associated mitochondrial DNA length mutations in human skin. Arch Dermatol Res 1995;287:641-8.

25. Berneburg M, Grether-Beck S, Kürten V, et al. Singlet oxygen mediates the UVA-induced generation of the photoaging-associated mitochondrial common deletion. J Biol Chem 1999;274:15345-9.

26. Krishnan KJ, Harbottle A, Birch-Machin MA. The use of a 3895 bp mitochondrial DNA deletion as a marker for sunlight exposure in human skin. J Invest Dermatol 2004;123:1020-4.

27. Krishnan KJ, Birch-Machin MA. The incidence of both tandem duplications and the common deletion in mtDNA from three distinct categories of sun-exposed human skin and in prolonged culture of fibroblasts. $J$ Invest Dermatol 2006;126:408-15.

28. McKenzie D, Bua E, McKiernan S, Cao Z, Aiken JM, Wanagat J. Mitochondrial DNA deletion mutations: a causal role in sarcopenia. Eur J Biochem 2002;269:2010-5.

29. Sen P, Shah PP, Nativio R, Berger SL. Epigenetic mechanisms of longevity and aging. Cell 2016;166:822-39.

30. Vandiver AR, Irizarry RA, Hansen KD, et al. Age and sun exposure-related widespread genomic blocks of hypomethylation in nonmalignant skin. Genome Biol 2015;16:80.

31. Bormann F, Rodríguez-Paredes M, Hagemann S, et al. Reduced DNA methylation patterning and transcriptional connectivity define human skin aging. Aging Cell 2016;15:563-71.

32. Ding S, Chen J, Zeng Q, et al. Chronic sun exposure is associated with distinct histone acetylation changes in human skin. Br J Dermatol 2018;179:110-7.

33. Zhou X, Zhuang Z, Wang W, et al. OGG1 is essential in oxidative stress induced DNA demethylation. Cell Signal 2016;28:1163-71.

34. Huh I, Zeng J, Park T, Yi SV. DNA methylation and transcriptional noise. Epigenetics Chromatin 2013;6:9.

35. Cheung P, Vallania F, Warsinske HC, et al. Single-cell chromatin modification profiling reveals increased epigenetic variations with aging. Cell 2018;173:1385-97.e14.

36. Richter T, von Zglinicki T. A continuous correlation between oxidative stress and telomere shortening in fibroblasts. Exp Gerontol 2007;42:1039-42.

37. Armanios M, Alder JK, Parry EM, Karim B, Strong MA, Greider CW. Short telomeres are sufficient to cause the degenerative defects associated with aging. Am J Hum Genet 2009;85:823-32.

38. Boonekamp JJ, Simons MJ, Hemerik L, Verhulst S. Telomere length behaves as biomarker of somatic redundancy rather than biological age. Aging Cell 2013;12:330-2.

39. Butler MG, Tilburt J, Devries A, et al. Comparison of chromosome telomere integrity in multiple tissues from subjects at different ages. Cancer Genetics and Cytogenetics 1998;105:138-44.

40. Friedrich U, Griese E, Schwab M, Fritz P, Thon K, Klotz U. Telomere length in different tissues of elderly patients. Mech Ageing Dev 2000;119:89-99.

41. Sugimoto M, Yamashita R, Ueda M. Telomere length of the skin in association with chronological aging and photoaging. J Dermatol Sci 2006;43:43-7.

42. Taylor RS, Ramirez RD, Ogoshi M, Chaffins M, Piatyszek MA, Shay JW. Detection of telomerase activity in malignant and nonmalignant skin conditions. J Invest Dermatol 1996;106:759-65.

43. Krunic D, Moshir S, Greulich-Bode KM, et al. Tissue context-activated telomerase in human epidermis correlates with little agedependent telomere loss. Biochim Biophys Acta 2009;1792:297-308.

44. Härle-Bachor C, Boukamp P. Telomerase activity in the regenerative basal layer of the epidermis inhuman skin and in immortal and carcinoma-derived skin keratinocytes. Proc Natl Acad Sci U S A 1996;93:6476-81.

45. Klaips CL, Jayaraj GG, Hartl FU. Pathways of cellular proteostasis in aging and disease. J Cell Biol 2018;217:51-63.

46. Sander CS, Chang H, Salzmann S, et al. Photoaging is associated with protein oxidation in human skin in vivo. J Invest Dermatol 2002;118:618-25.

47. Petropoulos I, Conconi M, Wang X, et al. Increase of oxidatively modified protein is associated with a decrease of proteasome activity and content in aging epidermal cells. J Gerontol A Biol Sci Med Sci 2000;55:B220-7.

48. Bulteau AL, Petropoulos I, Friguet B. Age-related alterations of proteasome structure and function in aging epidermis. Exp Gerontol 2000;35:767-77.

49. Chen L, Hu JY, Wang SQ. The role of antioxidants in photoprotection: a critical review. J Am Acad Dermatol 2012;67:1013-24.

50. Choi YJ. Shedding light on the effects of calorie restriction and its mimetics on skin biology. Nutrients 2020;12:E1529.

51. Singh B, Chatterjee A, Ronghe AM, Bhat NK, Bhat HK. Antioxidant-mediated up-regulation of OGG1 via NRF2 induction is associated with inhibition of oxidative DNA damage in estrogen-induced breast cancer. BMC Cancer 2013;13:253. 
52. Kwak MK, Wakabayashi N, Greenlaw JL, Yamamoto M, Kensler TW. Antioxidants enhance mammalian proteasome expression through the Keap1-Nrf2 signaling pathway. Mol Cell Biol 2003;23:8786-94.

53. Wu Y, Zheng X, Xu XG, et al. Protective effects of a topical antioxidant complex containing vitamins $\mathrm{C}$ and $\mathrm{E}$ and ferulic acid against ultraviolet irradiation-induced photodamage in Chinese women. J Drugs Dermatol 2013;12:464-8.

54. Darr D, Dunston S, Faust H, Pinnell S. Effectiveness of antioxidants (vitamin C and E) with and without sunscreens as topical photoprotectants. Acta Derm Venereol 1996;76:264-8.

55. Elmets CA, Singh D, Tubesing K, Matsui M, Katiyar S, Mukhtar H. Cutaneous photoprotection from ultraviolet injury by green tea polyphenols. J Am Acad Dermatol 2001;44:425-32.

56. Afaq F, Adhami VM, Ahmad N. Prevention of short-term ultraviolet B radiation-mediated damages by resveratrol in SKH-1 hairless mice. Toxicol Appl Pharmacol 2003;186:28-37.

57. Parrado C, Philips N, Gilaberte Y, Juarranz A, González S. Oral photoprotection: effective agents and potential candidates. Front Med (Lausanne) 2018;5:188.

58. Bjelakovic G, Nikolova D, Gluud LL, Simonetti RG, Gluud C. Antioxidant supplements for prevention of mortality in healthy participants and patients with various diseases. Sao Paulo Med J 2015;133:164-5.

59. Chung JH, Youn SH, Kwon OS, Cho KH, Youn JI, Eun HC. Regulations of collagen synthesis by ascorbic acid, transforming growth factor-beta and interferon-gamma in human dermal fibroblasts cultured in three-dimensional collagen gel are photoaging- and agingindependent. J Dermatol Sci 1997;15:188-200.

60. Orringer JS, Hammerberg C, Hamilton T, et al. Molecular effects of photodynamic therapy for photoaging. Arch Dermatol 2008;144:1296-302.

61. Manuskiatti W, Pattanaprichakul P, Inthasotti S, et al. Thermal response of in vivo human skin to fractional radiofrequency microneedle device. Biomed Res Int 2016;2016:6939018.

62. Sajjadi AY, Mitra K, Grace M. Expression of heat shock proteins 70 and 47 in tissues following short-pulse laser irradiation: assessment of thermal damage and healing. Med Eng Phys 2013;35:1406-14.

63. Mackanos MA, Contag CH. Pulse duration determines levels of Hsp70 induction in tissues following laser irradiation. J Biomed Opt 2011;16:078002.

64. McBride HM, Neuspiel M, Wasiak S. Mitochondria: more than just a powerhouse. Curr Biol 2006;16:R551-60.

65. Mellem D, Sattler M, Pagel-Wolff S, et al. Fragmentation of the mitochondrial network in skin in vivo. PLoS One 2017;12:e174469.

66. Prahl S, Kueper T, Biernoth T, et al. Aging skin is functionally anaerobic: importance of coenzyme Q10 for anti aging skin care. Biofactors 2008;32:245-55.

67. Hamanaka RB, Glasauer A, Hoover P, et al. Mitochondrial reactive oxygen species promote epidermal differentiation and hair follicle development. Sci Signal 2013;6:ra8.

68. Velarde MC, Flynn JM, Day NU, Melov S, Campisi J. Mitochondrial oxidative stress caused by Sod2 deficiency promotes cellular senescence and aging phenotypes in the skin. Aging (Albany NY) 2012;4:3-12.

69. Singh B, Schoeb TR, Bajpai P, Slominski A, Singh KK. Reversing wrinkled skin and hair loss in mice by restoring mitochondrial function. Cell Death Dis 2018;9:735.

70. Kenyon, CJ. The genetics of ageing. Nature 2010;464:504-12.

71. Barzilai N, Huffman DM, Muzumdar RH, Bartke A. The critical role of metabolic pathways in aging. Diabetes 2012;61:1315-22.

72. Choi YJ, Moon KM, Chung KW, et al. The underlying mechanism of proinflammatory NF- $\mathrm{kB}$ activation by the mTORC2/Akt/IKK $\alpha$ pathway during skin aging. Oncotarget 2016;7:52685-94.

73. Wu CL, Qiang L, Han W, Ming M, Viollet B, He YY. Role of AMPK in UVB-induced DNA damage repair and growth control. Oncogene 2013;32:2682-9.

74. Zhao P, Sui BD, Liu N, et al. Anti-aging pharmacology in cutaneous wound healing: effects of metformin, resveratrol, and rapamycin by local application. Aging Cell 2017;16:1083-93.

75. Golubtsova NN, Filippov FN, Gunin AG. Age-related changes in the content of sirtuin 1 in fibroblasts of human dermis. Adv Gerontol 2017;30:375-80.

76. Kalfalah F, Sobek S, Bornholz B, et al. Inadequate mito-biogenesis in primary dermal fibroblasts from old humans is associated with impairment of PGC1A-independent stimulation. Exp Gerontol 2014;56:59-68.

77. Kuehne A, Hildebrand J, Soehle J, et al. An integrative metabolomics and transcriptomics study to identify metabolic alterations in aged skin of humans in vivo. BMC Genomics 2017;18:169.

78. Randhawa M, Sangar V, Tucker-Samaras S, Southall M. Metabolic signature of sun exposed skin suggests catabolic pathway overweighs anabolic pathway. PLoS One 2014;9:e90367.

79. Coppé JP, Patil CK, Rodier F, Sun Y, Muñoz DP, et al. Senescence-associated secretory phenotypes reveal cell-nonautonomous functions of oncogenic RAS and the p53 tumor suppressor. PLoS Biol 2008;6:2853-68.

80. Krtolica A, Parrinello S, Lockett S, Desprez PY, Campisi J. Senescent fibroblasts promote epithelial cell growth and tumorigenesis: a link between cancer and aging. Proc Natl Acad Sci U S A 2001;98:12072-7.

81. Ressler S, Bartkova J, Niederegger H, et al. p16INK4A is a robust in vivo biomarker of cellular aging in human skin. Aging Cell 2006;5:379-89.

82. Castilho RM, Squarize CH, Chodosh LA, Williams BO, Gutkind JS. mTOR mediates Wnt-induced epidermal stem cell exhaustion and aging. Cell Stem Cell 2009;5:279-89.

83. Malaquin N, Vercamer C, Bouali F, et al. Senescent fibroblasts enhance early skin carcinogenic events via a paracrine MMP-PAR-1 axis. 
PLoS One 2013;8:e63607.

84. Weinmüllner R, Zbiral B, Becirovic A, et al. Organotypic human skin culture models constructed with senescent fibroblasts show hallmarks of skin aging. NPJ Aging Mech Dis 2020;6:4

85. Spindler M, Beal MF, Henchcliffe C. Coenzyme Q10 effects in neurodegenerative disease. Neuropsychiatr Dis Treat 2009;5:597-610.

86. Luo K, Yu JH, Quan Y, et al. Therapeutic potential of coenzyme Q $<$ sub $>10</$ sub $>$ in mitochondrial dysfunction during tacrolimusinduced beta cell injury. Sci Rep 2019;9:7995.

87. Knott A, Achterberg V, Smuda C, et al. Topical treatment with coenzyme Q10-containing formulas improves skin's Q10 level and provides antioxidative effects. Biofactors 2015;41:383-90.

88. Tan CL, Chin T, Tan CYR, Rovito HA, Quek LS, et al. Nicotinamide metabolism modulates the proliferation/differentiation balance and senescence of human primary keratinocytes. J Invest Dermatol 2019;139:1638-47.e3.

89. Kang HT, Hwang ES. Nicotinamide enhances mitochondria quality through autophagy activation in human cells. Aging Cell 2009;8:42638.

90. Beher D, Wu J, Cumine S, et al. Resveratrol is not a direct activator of SIRT1 enzyme activity. Chem Biol Drug Des 2009;74:619-24.

91. Cantó C, Gerhart-Hines Z, Feige JN, et al. AMPK regulates energy expenditure by modulating NAD+ metabolism and SIRT1 activity. Nature 2009;458:1056-60.

92. Um JH, Park SJ, Kang H, et al. AMP-activated protein kinase-deficient mice are resistant to the metabolic effects of resveratrol. Diabetes 2010;59:554-63.

93. Baur JA, Pearson KJ, Price NL, et al. Resveratrol improves health and survival of mice on a high-calorie diet. Nature 2006;444:337-42.

94. Csiszar A, Labinskyy N, Pinto JT, et al. Resveratrol induces mitochondrial biogenesis in endothelial cells. Am J Physiol Heart Circ Physiol 2009;297:H13-20.

95. Hung CF, Lin YK, Huang ZR, Fang JY. Delivery of resveratrol, a red wine polyphenol, from solutions and hydrogels via the skin. Biol Pharm Bull 2008;31:955-62.

96. Farris P, Krutmann J, Li YH, McDaniel D, Krol Y. Resveratrol: a unique antioxidant offering a multi-mechanistic approach for treating aging skin. J Drugs Dermatol 2013;12:1389-94.

97. Dierickx CC, Anderson RR. Visible light treatment of photoaging. Dermatol Ther 2005;18:191-208.

98. Karu TI, Pyatibrat LV, Kolyakov SF, Afanasyeva NI. Absorption measurements of a cell monolayer relevant to phototherapy: reduction of cytochrome c oxidase under near IR radiation. J Photochem Photobiol B 2005;81:98-106.

99. Karu T, Pyatibrat L, Kalendo G. Irradiation with He-Ne laser increases ATP level in cells cultivated in vitro. $J$ Photochem Photobiol B 1995;27:219-23.

100. Greco M, Guida G, Perlino E, Marra E, Quagliariello E. Increase in RNA and protein synthesis by mitochondria irradiated with heliumneon laser. Biochem Biophys Res Commun 1989;163:1428-34.

101. Yu W, Naim JO, Lanzafame RJ. The effect of laser irradiation on the release of bFGF from 3 T3 fibroblasts. Photochem Photobiol 1994;59:167-70.

102. Barolet D, Roberge CJ, Auger FA, Boucher A, Germain L. Regulation of skin collagen metabolism in vitro using a pulsed $660 \mathrm{~nm}$ LED light source: clinical correlation with a single-blinded study. J Invest Dermatol 2009;129:2751-9.

103. Sadick NS. A study to determine the efficacy of a novel handheld light-emitting diode device in the treatment of photoaged skin. $J$ Cosmet Dermatol 2008;7:263-7.

104. Russell BA, Kellett N, Reilly LR. A study to determine the efficacy of combination LED light therapy ( $633 \mathrm{~nm}$ and $830 \mathrm{~nm}$ ) in facial skin rejuvenation. J Cosmet Laser Ther 2005;7:196-200.

105. Soydas T, Yaprak Sarac E, Cinar S, et al. The protective effects of metformin in an in vitro model of aging 3 T3 fibroblast under the high glucose conditions. J Physiol Biochem 2018;74:273-81.

106. Rostamkalaei SS, Akbari J, Saeedi M, Morteza-Semnani K, Nokhodchi A. Topical gel of metformin solid lipid nanoparticles: a hopeful promise as a dermal delivery system. Colloids Surf B Biointerfaces 2019;175:150-7.

107. Chung CL, Lawrence I, Hoffman M, et al. Topical rapamycin reduces markers of senescence and aging in human skin: an exploratory, prospective, randomized trial. Geroscience 2019;41:861-9.

108. Blagosklonny MV. Rapamycin for longevity: opinion article. Aging (Albany NY) 2019;11:8048-67.

109. Baker DJ, Wijshake T, Tchkonia T, et al. Clearance of p16Ink4a-positive senescent cells delays ageing-associated disorders. Nature 2011;479:232-6.

110. Baker DJ, Childs BG, Durik M, et al. Naturally occurring p16(Ink4a)-positive cells shorten healthy lifespan. Nature 2016;530:184-9.

111. Wang Y, Chang J, Liu X, Zhang X, Zhang S, Zhang X, Zhou D, Zheng G. Discovery of piperlongumine as a potential novel lead for the development of senolytic agents. Aging (Albany NY) 2016;8:2915-26.

112. Zhu Y, Tchkonia T, Fuhrmann-Stroissnigg H, et al. Identification of a novel senolytic agent, navitoclax, targeting the Bcl-2 family of antiapoptotic factors. Aging Cell 2016;15:428-35.

113. Zhu Y, Tchkonia T, Pirtskhalava T, Gower AC, Ding H, et al. The Achilles' heel of senescent cells: from transcriptome to senolytic drugs. Aging Cell 2015;14:644-58.

114. Toutfaire M, Bauwens E, Debacq-Chainiaux F. The impact of cellular senescence in skin ageing: A notion of mosaic and therapeutic strategies. Biochem Pharmacol 2017;142:1-12.

115. Karin M, Ben-Neriah Y. Phosphorylation meets ubiquitination: the control of NF-[kappa]B activity. Annu Rev Immunol 2000;18:621-63.

116. Adler AS, Sinha S, Kawahara TL, Zhang JY, Segal E, et al. Motif module map reveals enforcement of aging by continual NF-kappaB activity. Genes Dev 2007;21:3244-57. 
117. Han KH, Choi HR, Won CH, et al. Alteration of the TGF-beta/SMAD pathway in intrinsically and UV-induced skin aging. Mech Ageing Dev 2005;126:560-7.

118. Muffler S, Stark HJ, Amoros M, et al. A stable niche supports long-term maintenance of human epidermal stem cells in organotypic cultures. Stem Cells 2008;26:2506-15.

119. Giangreco A, Qin M, Pintar JE, Watt FM. Epidermal stem cells are retained in vivo throughout skin aging. Aging Cell 2008;7:250-9.

120. Rittié L, Stoll SW, Kang S, Voorhees JJ, Fisher GJ. Hedgehog signaling maintains hair follicle stem cell phenotype in young and aged human skin. Aging Cell 2009;8:738-51.

121. Doles J, Storer M, Cozzuto L, Roma G, Keyes WM. Age-associated inflammation inhibits epidermal stem cell function. Genes Dev 2012;26:2144-53.

122. Giangreco A, Goldie SJ, Failla V, Saintigny G, Watt FM. Human skin aging is associated with reduced expression of the stem cell markers beta1 integrin and MCSP. J Invest Dermatol 2010;130:604-8.

123. Iriyama S, Yasuda M, Nishikawa S, Takai E, Hosoi J, Amano S. Decrease of laminin-511 in the basement membrane due to photoaging reduces epidermal stem/progenitor cells. Sci Rep 2020;10:12592.

124. Kwon OS, Yoo HG, Han JH, Lee SR, Chung JH, et al. Photoaging-associated changes in epidermal proliferative cell fractions in vivo. Arch Dermatol Res 2008;300:47-52.

125. Gannon HS, Donehower LA, Lyle S, Jones SN. Mdm2-p53 signaling regulates epidermal stem cell senescence and premature aging phenotypes in mouse skin. Dev Biol 2011;353:1-9.

126. Fitzpatrick RE, Rostan EF. Reversal of photodamage with topical growth factors: a pilot study. $J$ Cosmet Laser Ther 2003;5:25-34.

127. Ehrlich M, Rao J, Pabby A, Goldman MP. Improvement in the appearance of wrinkles with topical transforming growth factor beta(1) and 1-ascorbic acid. Dermatol Surg 2006;32:618-25.

128. Gold MH, Goldman MP, Biron J. Efficacy of novel skin cream containing mixture of human growth factors and cytokines for skin rejuvenation. J Drugs Dermatol 2007;6:197-201.

129. Bos JD, Meinardi MM. The 500 Dalton rule for the skin penetration of chemical compounds and drugs. Exp Dermatol 2000;9:165-9.

130. Griffiths CE, Russman AN, Majmudar G, Singer RS, Hamilton TA, Voorhees JJ. Restoration of collagen formation in photodamaged human skin by tretinoin (retinoic acid). N Engl J Med 1993;329:530-5.

131. Weinstein GD, Nigra TP, Pochi PE, et al. Topical tretinoin for treatment of photodamaged skin. A multicenter study. Arch Dermatol 1991;127:659-65.

132. Fan Y, Choi TH, Chung JH, Jeon YK, Kim S. Hyaluronic acid-cross-linked filler stimulates collagen type 1 and elastic fiber synthesis in skin through the TGF- $\beta /$ Smad signaling pathway in a nude mouse model. J Plast Reconstr Aesthet Surg 2019;72:1355-62.

133. Quan T, Wang F, Shao Y, et al. Enhancing structural support of the dermal microenvironment activates fibroblasts, endothelial cells, and keratinocytes in aged human skin in vivo. J Invest Dermatol 2013;133:658-67.

134. Courderot-Masuyer C, Robin S, Tauzin H, Humbert P. Evaluation of lifting and antiwrinkle effects of calcium hydroxylapatite filler. In vitro quantification of contractile forces of human wrinkle and normal aged fibroblasts treated with calcium hydroxylapatite. $J$ Cosmet Dermatol 2016;15:260-8.

135. Shin JJ, Park TJ, Kim BY, et al. Comparative effects of various absorbable threads in a rat model. J Cosmet Laser Ther 2019;21:158-62.

136. Yoon JH, Kim SS, Oh SM, Kim BC, Jung W. Tissue changes over time after polydioxanone thread insertion: An animal study with pigs. $J$ Cosmet Dermatol 2019;18:885-91.

137. Freedman BM, Rueda-Pedraza E, Waddell SP. The epidermal and dermal changes associated with microdermabrasion. Dermatol Surg 2001;27:1031-3;1033-4.

138. Abdel-Motaleb AA, Abu-Dief EE, Hussein MR. Dermal morphological changes following salicylic acid peeling and microdermabrasion. J Cosmet Dermatol 2017;16:e9-14.

139. Rosenberg GJ, Brito MA Jr, Aportella R, Kapoor S. Long-term histologic effects of the CO2 laser. Plast Reconstr Surg 1999;104:223944;2245-6.

140. Kim D, Chen R, Sheu M, et al. Noncoding dsRNA induces retinoic acid synthesis to stimulate hair follicle regeneration via TLR3. Nat Commun 2019;10:2811.

141. Macaulay IC, Carr P, Gusnanto A, Ouwehand WH, Fitzgerald D, Watkins NA. Platelet genomics and proteomics in human health and disease. J Clin Invest 2005;115:3370-7.

142. Pavlovic V, Ciric M, Jovanovic V, Stojanovic P. Platelet Rich Plasma: a short overview of certain bioactive components. Open Med (Wars) 2016;11:242-7.

143. Maisel-Campbell AL, Ismail A, Reynolds KA, et al. A systematic review of the safety and effectiveness of platelet-rich plasma (PRP) for skin aging. Arch Dermatol Res 2020;312:301-15.

144. Yang R, Liu F, Wang J, Chen X, Xie J, Xiong K. Epidermal stem cells in wound healing and their clinical applications. Stem Cell Res Ther 2019;10:229.

145. Charles-de-Sá L, Gontijo-de-Amorim NF, Rigotti G, et al. Photoaged skin therapy with adipose-derived stem cells. Plast Reconstr Surg 2020;145:1037e-49.

146. Son WC, Yun JW, Kim BH. Adipose-derived mesenchymal stem cells reduce MMP-1 expression in UV-irradiated human dermal fibroblasts: therapeutic potential in skin wrinkling. Biosci Biotechnol Biochem 2015;79:919-25. 